\title{
Chair and Bed Rise Performance in ADL-Impaired Congregate Housing Residents.
}

\author{
N.B. Alexander, MD, ${ }^{* \neq}$ A.T. Galecki, MD, PhD, ${ }^{* \neq}$ L.V. Nyquist, PhD, ${ }^{\ddagger}$ M.R. Hofmeyer, BS, ${ }^{\dagger} J . C$. \\ Grunawalt, MS, RCNS, ${ }^{\dagger}$ M.L. Grenier, BA, ${ }^{\dagger}$ and J.L. Medell, BS, MPT ${ }^{\dagger}$
}

OBJECTIVES: To examine the ability of activity of daily living (ADL)-impaired older adults to successfully rise, and, when successful, the time taken to rise, from a bed and chair under varying rise task demands.

\section{SETTING: Seven congregate housing facilities}

SUBJECTS: Congregate housing residents $(\mathrm{n}=116$, mean age 82 ) who admitted to requiring assistance (such as from a person, equipment, or device) in performing at least one of the following mobility-related ADLs: transferring, walking, bathing, and toileting.

METHODS: Subjects performed a series of bed and chair rise tasks where the rise task demand varied according to the head of bed (HOB) height, chair seat height, and use of hands. Bed rise tasks included supine to sit-to-edge, sit up in bed with hand use, and sit up in bed without hands, all performed from a bed where the $\mathrm{HOB}$ was adjusted to 0,30 , and $45^{\circ}$ elevations; roll to side-lying then rise $\left(\mathrm{HOB} 0^{\circ}\right)$; and supine to stand $\left(\mathrm{HOB} 0^{\circ}\right)$. Chair seat heights were adjusted according to the percent of the distance between the floor and the knee ( $\%$ FK), and included rises (1) with hands and then without hands at $140,120,100$, and $80 \% \mathrm{FK}$; (2) from a reclining $\left(105^{\circ}\right.$ at chair back) and tilting (seat tilted $10^{\circ}$ posteriorly) chair (100\% FK); and (3) from a $80 \%$ FK seat height with a 4-inch cushion added, with and then without hands. Logistic regression for repeated measures was used to test for differences between tasks in the ability to rise. After log transformation of rise time, a linear effects model was used to compare rise time between tasks.

RESULTS: The median total number of tasks successfully completed was 18 (range, 3-21). Nearly all subjects were able to rise from positions where the starting surface was elevated as long as hand use was unlimited. With the $\mathrm{HOB}$ at 30 or $45^{\circ}$ essentially all subjects could complete supine to sit-to-edge and sit up with hands. Essentially all subjects could rise from a seat height at 140,120 , and $100 \%$ FK as long as hand use was allowed. A small group (8-10\%) of subjects was dependent upon hand use to perform the least challenging tasks, such as $140 \%$ FK without hands chair rise and $45^{\circ}$ sit up

From the "Geriatric Research, Education and Clinical Center, Department of Veterans Affairs Medical Center; tDivision of Geriatric Medicine, Department of Internal Medicine, The University of Michigan; $\ddagger$ the Institute of Gerontology, The University of Michigan, Ann Arbor, Michigan.

Address correspondence to Neil B. Alexander, MD, Division of Geriatric Medicine, Department of Internal Medicine, 1111 CCGCB, 1500 E. Medical Center Dr., Ann Arbor, MI 48109-0926. without hands. This dependency upon hand use increased significantly as the demand of the task increased, that is, as the $\mathrm{HOB}$ or seat height was lowered. Approximately threequarters of the sample could not rise from a flat $\left(0^{\circ} \mathrm{HOB}\right.$ elevation) bed or low ( $80 \% \mathrm{FK}$ ) chair when hand use was not allowed. Similar trends were seen in rise performance time, that is, performance times tended to increase as the $\mathrm{HOB}$ or chair seat elevation declined and as hand use was limited. Total self-reported ADL disability, compared to the single $\mathrm{ADL}$ transferring item, was a stronger predictor of rise ability and timed rise performance, particularly for chair rise tasks. CONCLUSIONS: Lowering $\mathrm{HOB}$ height and seat height increased bed and chair rise task difficulty, particularly when hand use was restricted. Restricting hand use in low HOB height or lowered seat height conditions may help to identify older adults with declining rise ability. Yet, many of those who could not rise under "without hands" conditions could rise under "with hands" conditions, suggesting that dependency on hand use may be a marker of progressive rise impairment but may not predict day-to-day natural milieu rise performance. Intertask differences in performance time may be statistically significant but are clinically small. Given the relationship between self-reported ADL disability and rise performance, impaired rise performance may be considered a marker for ADL disability. These bed and chair rise tasks can serve as outcomes for an intervention to improve bed and chair rise ability and might also be used in future studies to quantify improvements or declines in function over time, to refine physical therapy protocols, and to examine the effect of bed and chair design modifications on bed and chair rise ability. J Am Geriatr Soc 48:526-533, 2000.

Key words: activities of daily living; geriatric assessment; bed rest

$\mathrm{D}$ ifficulty in transferring, that is, the ability to move into and out of a chair or bed, is common in those aged 65 and over, affecting over $6 \%$ of community-dwelling older adults, ${ }^{1}$ and over $60 \%$ of nursing home residents. ${ }^{2}$ Transferring is considered a basic activity of daily living (ADL) that is a standard part of geriatric assessment. Assessment of transferring is generally descriptive, based on requirements of the individual for assistance from a caregiver or device, that is, whether or not assistance is required from the caregiver or device. These currently used descriptive, categorical scales 
may not be able to detect subtle, clinically significant changes in function or to quantify mild-to-moderate ranges of impairment. ${ }^{3-5}$ Transferring function may decline as a result of acute illness and hospitalization, ${ }^{6}$ or analogously, improve as a result of rehabilitation. A battery that includes transferring tasks for hospitalized older adults, but using a categorical scale that presumably would not detect milder impairments or subtle decline, has recently been published ${ }^{7}$ and used to identify those at risk for decline in physical performance after hospitalization. ${ }^{8}$ More quantitative methods, such as determining rise success, and, when successful, the time taken to rise during a battery of transferring tasks may be useful (1) in quantifying mild-to-moderate transferring impairment and (2) in detecting more subtle yet clinically significant declines or improvements in transferring function.

In designing a quantitative battery of transferring performance, we drew upon previous studies of how older adults rose from a sit-to-stand position and from a supine-to-sit position. Aspects of chair configuration, such as lowered seat height, increased posterior seat tilt and backrest recline, and increased seat compressibility disproportionately increased the time required to rise in old versus young adults. ${ }^{9}$ Success in rising from a chair in older adults seemed to increase as the seat height is raised. ${ }^{10}$ Furthermore, the inability to rise from a chair without use of hand support (usually on armrests) serves to identify older adults with reduced sit-to-stand ability. ${ }^{11-13}$ In regard to rising from a supine to sitting position, and compared to healthy older adults, frail congregate housing older adults take longer to rise from a supine to sitting position. ${ }^{14} \mathrm{~A}$ subgroup of independent older adults with altered rising patterns from a supine position were identified based on their inability to sit up in bed without the use of their hands. ${ }^{15}$ Although two frail older adult groups, congregate housing residents and nursing home residents undergoing rehabilitation, were able to rise from supine to sitting at the edge of the bed, ${ }^{16}$ the nursing home residents were more likely to have difficulty doing bed mobility tasks, such as sitting up in bed, even with the head of the bed (HOB) elevated to $30^{\circ}$. Thus, by altering aspects of the chair or bed apparatus (such as by raising or lowering the performance surface) or by constraining aspects of performance (such as by limiting the use of hand support), a battery of chair rise and bed rise tasks of varying difficulty was developed. Some of these tasks were easy enough for disabled subjects to complete and some might challenge relatively healthy old adults.

These bed and chair rise tasks might be used to quantify improvements in function or as refinements in exercise protocols used during traditional physical therapy programs. In addition, critical bed and chair design parameters that are modifiable, such as seat height and HOB elevation, are embedded in these tasks. Our data may thus have an impact on future design specifications of living environments for older adults who are mobility impaired or undergoing rehabilitation, such as in a nursing home or assisted-living milieu.

This report focuses on the chair rise and bed rise performance of a group of ADL-impaired congregate housing residents enrolled in an exercise program to improve their chair and bed rise ability. This paper includes only baseline data; future work will detail the actual intervention and outcomes. For these ADL-impaired older adults, we hypothesized that lowering the height of the HOB, lowering the chair seat height, and restricting hand use would increase rise difficulty, as measured by decreased success in rising and, if successful in rising, by increased time needed to complete the rise.

\section{METHODS}

\section{Subjects}

Older adult residents (aged 65 and over) of congregate housing facilities in southeastern Michigan were recruited to participate in an exercise program designed to improve their ability to rise from a bed and a chair. Subjects were screened to be medically stable but have certain self-reported ADLrelated mobility dependency (see below).

Subjects underwent a medical history and physical examination, using standardized cardiovascular, ${ }^{17}$ musculoskeletal ${ }^{18}$ and neurological ${ }^{19}$ evaluations, conducted by a nurse clinician. Those eligible for participation were or had:

Able to follow simple commands and cooperate with the protocol. That is, able to hear commands, able to see the apparatus, not agitated or uncooperative (as judged by the nurse clinician).

No unstable cardiorespiratory status, such as chest pain and marked dyspnea.

No acute infection or inflammation, such as acute joint pain flare.

Relatively untrained, that is, not participating in regular strenuous activity such as aerobics.

Occasional walking for leisure; up to one-half mile per day was acceptable.

No substantial cognitive impairment, that is, Folstein Mini-Mental State Examination (MMSE) score $>23$ out of $30 .{ }^{20}$

No depression based on Geriatric Depression Scale (GDS) short-form, that is, score of $\leq 4$ out of $15 .^{21}$

\section{Self-Reported Functional Assessment and Inclusion Criteria}

We chose four mobility-related ADL tasks, namely transferring, bathing, toileting, and walking, and recruited congregate housing residents who reported needing assistance (such as from a person, equipment, or device), that is, were dependent, in performing these ADL tasks, as per a standardized instrument used in the Established Populations for the Epidemiological Study of the Elderly (EPESE) studies. ${ }^{22}$ Dependency in some or all of these four mobility-related ADLs (transferring, bathing, toileting, and walking) is highly interrelated, based on how this group of disabilities clusters together on factor analysis ${ }^{23}$ and how this group of disabilities can be predicted by physical performance tests. ${ }^{24,25}$ Although the present study focused on transferring and some of these subjects denied dependency in transferring, dependency in the other three ADLs relates directly to timed chair rise performance, ${ }^{24,25}$ an outcome variable in the present study. These subjects represent a cohort of disabled residents who maintain themselves in a congregate housing facility. They would thus benefit from interventions to maintain their independence and be motivated to improve or maintain their independence, that is, an ideal cohort for training. Accordingly, residents who admitted to requiring assistance in the four mobility-related ADLs (transferring, bathing, toileting, and walking) were included in the study cohort. Note that 
other ADLs (such as dressing, grooming, and eating) were also assessed but not used for inclusion criteria.

Reports of disability on an additional eight mobilityrelated items were also assessed, as per the standardized instrument. ${ }^{22}$ Subjects reported their ability or inability to perform three Rosow-Breslau items (ability to do heavy work around the house, walk up and down stairs to the second floor, and walk half a mile without help) and any difficulty encountered with performing five Nagi items (pulling or pushing large objects; stooping, crouching, or kneeling; carrying weights over $10 \mathrm{lbs}$; reaching or extending arms above shoulder level; writing or handling or fingering small objects).

Seven congregate housing facilities throughout southeastern Michigan were involved. All residents were sent a letter describing the exercise program and asked to respond regarding their functional status if they were interested in participating. Of 1508 residents contacted, 374 completed the ADL screening and 187 of these $374(50 \%)$ were found to be eligible based on reports of dependency in mobility-related ADLs (see above). Of these 187, 36 refused to participate in the exercise program, 24 were excluded after the nurse clinician screening (see above), and 127 were ultimately randomized to participate. These 127 subjects underwent two baseline test sessions 1 week apart, with 11 subjects dropping out after the first baseline test, leaving the final cohort of $\mathbf{1 1 6}$. These last dropouts occurred for a variety of reasons, such as being too busy, losing interest, or having an acute medical problem; no injuries occurred with testing that might have led to dropouts.

\section{Bed Rise and Chair Rise Tasks}

The bed rise and chair rise tasks were chosen because of their relevance to the daily challenges faced by many older adults. The easier tasks reflect situations where raising the $\mathrm{HOB}$ and seat height can facilitate the rise; the more difficult tasks tap into the ability to rise under common challenging situations.

Subjects started in the prescribed initial configuration and then were told to make whatever movements necessary to complete the rise at a comfortable pace. The tasks were performed in the order of what we estimated to be the approximate degree of difficulty that subjects might encounter with each task. Using a set task order helped to control for subject fatigue effects, because the easiest tasks were presented first and all subjects performed the tasks in the same order.

Subjects completed a task successfully when they reached the end position safely without experimenter facilitation and without violations (such as touching the upper extremities to the bed surface when sitting up without hand use). Subjects who failed to perform a task had a 1-minute rest period, after which the task trial was repeated. After a second failed attempt, subjects moved to the next task. Although the ability to successfully complete a rise task was an important outcome, time to complete the rise task also provided key information regarding task performance. All timing data were acquired by a technician using a hand-held stopwatch.

\section{Bed Rise Tasks}

All bed rise tasks were performed on a controlled surface, a 78-in $\times 36$-in plywood plinth with 1 -in padding, attached to a wooden frame so that the floor to top surface height was 26 in. The plinth was hinged so that the top section could be raised. Unless noted otherwise below, subjects started from an initial supine configuration with arms extended at their sides, hips adducted, legs extended, and feet together. Each of the supine to sitting and sit-up tasks was performed with the HOB in one of three positions: at 0,30 , and $45^{\circ}$ elevations. Unless otherwise noted, subjects had full, unrestricted use of their upper extremities to facilitate rising. The actual order of performance differed from what appears below, in that all tasks were performed from easier to more difficult, that is, tasks were performed at $45^{\circ}$ elevations before dropping to $30^{\circ}$.

Supine to sit-to-edge: this task entailed rising from supine ( $\mathrm{HOB} 45,30$, and $0^{\circ}$ ) to sit at the edge of the bed with legs dangling.

Sit up, with hands: starting with knees and hips flexed, participants rose from supine (HOB 45,30 , and $0^{\circ}$ ) to sit while keeping the legs in the bed.

Sit up, without hands: starting with knees and hips flexed, participants rose from supine ( $\mathrm{HOB} 45,30$, and $0^{\circ}$ ) to sit while keeping the legs in the bed, with arms folded across the chest.

Roll to side-lying then rise: participants rolled onto their side $\left(\mathrm{HOB} 0^{\circ}\right)$ and then rose from a side-lying position to sitting on the edge of the bed.

Supine to stand: this task required rising from supine ( $\mathrm{HOB}$ $\left.0^{\circ}\right)$ to stand on the floor at the edge of the bed.

\section{Chair Rise Tasks}

All chair rise tasks were performed using a laboratory chair that could be adjusted for seat height and tilt. ${ }^{9}$ Unless otherwise noted, each subject sat upright with thighs horizontal, anterior seat edge support at the midpoint of the femur, $80^{\circ}$ knee flexion, $10^{\circ}$ ankle dorsiflexion, and feet flat on the floor, laterally separated by one foot length. The backrest was rotated slightly so that the subject sat back at the initial position with $5^{\circ}$ of trunk extension, but with no significant posterior pelvic tilt. When hand use was allowed, arm rests were placed so that there was no flexion or extension at the shoulder and the forearms and hands were horizontal. The seat surface was firm and had no anteriorposterior slope. Chair seat height was adjusted to percents of floor to knee (lateral condyle) height (abbreviated as \% FK).

The standard starting seat height configuration was at $100 \%$ FK. In the 140 and $120 \%$ FK conditions, simulating a posture between sitting and standing $(140 \%)$ and a typical elevated seat $(120 \%)$, feet were still flat on the floor but only the ischial tuberosities were in contact with a seat that was more shallow $(20 \mathrm{~cm})$. Without the shallow seat, some subjects could not contact the floor with their feet. Additional chair rise challenge was provided when seat tilt $\left(105^{\circ}\right.$ vs standard $\left.90^{\circ}\right)$ and backrest recline $\left(10^{\circ}\right.$ vs standard $\left.5^{\circ}\right)$ were added to the $100 \% \mathrm{FK}$ position, simulating a semi-reclining position. Addition of a block of 4-in upholstery foam to $80 \%$ FK simulated a soft-cushioned chair or sofa. The actual order of performance differed from what appears below, in that all tasks are performed from easier to more difficult, that is, tasks are performed at $140 \%$ elevations before dropping to $120 \%$. Hand use on the armrests was unrestricted, except in without hand situations when arms were folded across the chest. 
Rise from different heights, with hands $(140,120,100$, and $80 \%$ FK)

Rise from recline/tilt chair, with hands $(100 \% \mathrm{FK})$ : subjects rose from a chair with the seat tilted $10^{\circ}$ posteriorly and the chair back recline at $105^{\circ}$.

Rise from different heights, without hands $(140,120,100$, and $80 \% \mathrm{FK}$ )

Rise from $80 \%$ FK with 4-in cushion on seat, with hands and without hands: participants rose from a chair with the seat at $80 \%$ height and a 4 -in block of foam placed on the seat.

\section{Data Analysis}

All rise task data presented here represents baseline, preintervention performance. For the bed rise tasks, we examined the effect of raising the $\mathrm{HOB}$ and use of hands on rise success, and, when successful, on the time taken to rise. Similarly, for the chair rise tasks, we examined the effect of chair seat height and use of hands on rise success, and, when successful, on the time taken to rise. In addition, because some of the rise tasks were quite easy (most were successful) and some of the rise tasks were quite difficult (few were able to rise), the number of tasks successfully completed, a total task score, was also computed. These effects were analyzed after adjusting for the self-reported ADL disability items above and, specifically, the disability in transfers item. Logistic regression for repeated measures was used in analyses of rise success because of the several dichotomous outcomes measured under different conditions. Calculations were performed using the SAS/GENMOD procedure. The corresponding methodology is known as generalized estimating equations (GEE) method. ${ }^{26} \mathrm{~A}$ linear mixed effects mode ${ }^{27}$ was used in analyses of rise time because several continuous variables were measured under different conditions. Calculations were performed using the SAS/MIXED procedure. Because of the skewed distributions, rise times were logtransformed.
The focus of these models was on dependent variables arranged in the following manner: (1) a three-by-three table spanned by three bed rise tasks, namely supine to sit-to-edge, sit up with hands, and sit up without hands, and for three HOB heights, 0,30 , and $45^{\circ}$; and (2) a four-by-two table spanned by four chair rise tasks, namely 140,120,100, and $80 \% \mathrm{FK}$ tabulated according to hand or no hand use. For analysis purposes, the seat height was considered a continuous variable so that the regression estimate represents a difference in rise time (measured on the log scale) per $1 \%$ of seat height change.

To determine test-retest reliability, all subjects were retested 1 week after baseline testing. Simple Kappa statistics are presented for able versus unable to rise data, whereas intraclass correlation coefficients are presented for logtransformed rise time data.

\section{RESULTS}

\section{Subjects}

Data from a total of 116 subjects (mean $\pm S D$ age $82 \pm$ 7; range, 69-94) are presented here (see Table 1). Subjects admitted to dependency in an average of nearly three (2.8) mobility-related ADLs. Dependency was noted most commonly in walking $(74 \%)$, followed by bathing $(66 \%)$, toileting $(57 \%)$, and transferring $(48 \%)$. Eighteen percent admitted to dependency in two of these ADLs, whereas $22 \%$ and $16 \%$ admitted to dependency in three and four of these ADLs, respectively. Given that this was a noninstitutionalized cohort, the percent of subjects admitting to other basic ADL disabilities was smaller, that is, dressing ( $16 \%)$, grooming $(11 \%)$, and eating $(9 \%)$. Substantial disability was also reported in terms of the Rosow-Breslau and Nagi items. Subjects reported the inability to perform a mean of 2.4 Rosow-Breslau items (range, 0-3) and difficulty in performing 3.6 (range, 1-5) Nagi items. Nearly all subjects (95\%) admitted to difficulty in stooping, crouching, or kneeling, and, with the exception of the last two Nagi items (reaching or extending arms above shoulder level, and writing or handling small objects), at least two-thirds of the sample reported

Table 1. Subject Description

$\mathrm{N}$ (females/males)

Age in years-mean \pm SD (range)

Body mass index $\left(\mathrm{kg} / \mathrm{m}^{2}\right)$-mean $\pm \mathrm{SD}$ (range)

No. of ADL dependency-Mean $\pm S D$ (range)

Dependency in:

Walking

Bathing

Tolleting

Transferring

1 ADL

2 ADLs

3 ADLs

4 or more ADLs

No. Rosow-Breslau items unable-mean \pm SD (range)

No. Nagi items with difficulty-mean \pm SD (range)

Folstein Mini-Mental Status-mean \pm SD

POMA* score-mean \pm SD
$116(101 / 15)$

$82.1 \pm 6.6(69-93)$

$27.5 \pm 5.8(17-53)$

$2.8 \pm 1.7(1-7)$

$74 \%$

$66 \%$

$57 \%$

$48 \%$

$30 \%$

$18 \%$

$22 \%$

$30 \%$

$2.4 \pm 0.9(0-3)$

$3.6 \pm 1.2(1-5)$

$27.5 \pm 2.5$

$18.8 \pm 6.4$

*A screening measure of balance and gait impairment ${ }^{35}$. 
Table 2. Number (\%) Unable to Successfully Complete Bed and Chair Rise Task

\begin{tabular}{|c|c|c|c|}
\hline \multirow[b]{2}{*}{ Bed Rise Task ${ }^{\star}$} & \multicolumn{3}{|c|}{ Starting Positions* } \\
\hline & $45^{\circ}$ & $30^{\circ}$ & $0^{\circ}$ \\
\hline $\begin{array}{l}\text { Supine to sit-to-edge } \\
\text { Sit-up, with hands } \\
\text { Sit-up, without hands } \\
\text { Side-lying to sit } \\
\text { Supine-to-stand }\end{array}$ & $\begin{array}{c}1(1) \\
1(1) \\
12(10)\end{array}$ & $\begin{array}{c}1(1) \\
1(1) \\
19(16)\end{array}$ & $\begin{array}{l}4(3) \\
6(5) \\
90(74) \\
10(8) \\
6(5)\end{array}$ \\
\hline
\end{tabular}

\begin{tabular}{lcc}
\hline & \multicolumn{2}{c}{ Use of Hands $^{*}$} \\
\cline { 2 - 3 } Chair Rise Task & With Hands & Without Hands \\
\hline $140 \%$ & $1(1)$ & $10(8)$ \\
$120 \%$ & $1(1)$ & $23(18)$ \\
$100 \%$ & $1(1)$ & $39(32)$ \\
$100 \%$, tilt/recline & $5(4)$ & $39(45)$ \\
$80 \%$, cushion & $5(4)$ & $94(77)$ \\
\hline
\end{tabular}

${ }^{*}$ For bed rise tasks, starting position is the elevation of the head of the bed relative to the horizontal, $0^{\circ}$ no elevation, $30^{\circ}$ elevation, and $45^{\circ}$ elevation. For chair rise tasks, tasks were performed both with and withour use of hands on armrests, and starting position is given in percent of floor to knee height, resulting in a range from high (140\%) to low $(80 \%)$ seat heights. For additional description of tasks, see text.

disability on the remainder of the Rosow-Breslau and Nagi items.

\section{Bed Rise and Chair Rise Task Performance Ability}

The total number of bed and chair rise tasks successfully completed ranged from 3 to 21 , with a median score of 18 . The majority of subjects completed between 17 and 20 tasks, leaving $19 \%$ of subjects who completed 16 tasks or less, and $5 \%$ of subjects who completed all 21 tasks.

Nearly all subjects were able to rise from positions where the starting surface was elevated as long as hand use was unlimited (see Table 2). With the HOB at 30 or $45^{\circ}$, essentially all subjects could complete supine to sit-to-edge and sit up with hands. Essentially all subjects could rise from a seat height at 140,120 , and $100 \%$ FK as long as hand use was allowed.

A small group (8-10\%) of subjects was dependent upon hand use to perform the least challenging tasks, such as $140 \%$ without hands chair rise and $45^{\circ}$ sit up without hands. This dependency upon hand use increased significantly as the demand of the task increases, that is, as the HOB or seat height was lowered. Subjects were less likely to sit up in $0^{\circ}$ HOB compared to $45^{\circ} \mathrm{HOB}$ during with hands (GEE parameter estimate $\pm \mathrm{SE}-1.923 \pm 0.91, P<.05)$ and without hands $(-3.35 \pm 0.375, P<.0001)$. Subjects were also less likely to sit up during without hands $30^{\circ}$ versus $45^{\circ}$ $(-0.568 \pm 0.217, P<.01)$. For the chair rise tasks, a model comparing $140,120,100$, and $80 \%$ FK rises showed no significant effect when hand use was allowed. However, when hand use was not allowed, a significant drop in rise ability occurred as the chair was lowered $(-0.066 \pm 0.0072, P<$ $.0001)$. Approximately three-quarters of the sample could not rise from a flat $\left(0^{\circ} \mathrm{HOB}\right.$ elevation) bed or low $(80 \% \mathrm{FK})$ chair when hand use was not allowed.

A small group $(5 \%)$ of subjects was also unable to rise from a supine to standing position, even at $0^{\circ} \mathrm{HOB}$ elevation. Similarly a small group of subjects $(7-8 \%)$ was unable to rise
Table 3. Mean (SD) Bed and Chair Rise Task Performance Time (in Seconds)

\begin{tabular}{|c|c|c|c|}
\hline \multirow[b]{2}{*}{ Bed Rise Task* } & \multicolumn{3}{|c|}{ Starting Positions* } \\
\hline & $45^{\circ}$ & $30^{\circ}$ & $0^{\circ}$ \\
\hline $\begin{array}{l}\text { Supine to sit-to-edge } \\
\text { Sit-up, with hands } \\
\text { Sit-up, without hands } \\
\text { Side-lying to sit } \\
\text { Supine-to-stand }\end{array}$ & $\begin{array}{l}5.3(3.5) \\
2.1(0.8) \\
2.0(0.7)\end{array}$ & $\begin{array}{l}6.0(4.3) \\
2.6(1.2) \\
2.9(1.8)\end{array}$ & $\begin{array}{c}6.8(3.7) \\
4.2(2.2) \\
4.6(2.1) \\
9.7(7.2) \\
15.2(18.1)\end{array}$ \\
\hline & \multicolumn{3}{|c|}{ Use of Hands* } \\
\hline Chair Rise Task* & With Hands & Wit & out Hands \\
\hline $\begin{array}{l}140 \% \\
120 \% \\
100 \% \\
100 \% \text {, tilt/recline } \\
80 \% \text {, cushion } \\
80 \%\end{array}$ & $\begin{array}{l}2.7(1.5) \\
3.4(2.2) \\
3.8(4.0) \\
4.1(2.3) \\
4.1(3.6) \\
5.7(4.8)\end{array}$ & & $\begin{array}{l}.9(1.5) \\
4.3(3.6) \\
4.6(3.4)\end{array}$ \\
\hline
\end{tabular}

*For bed rise tasks, starting position is the elevation of the head of the bed relative to the horizontal, $0^{\circ}$ no elevation, $30^{\circ}$ elevation, and $45^{\circ}$ elevation. For chair rise tasks, tasks were performed both with and without use of hands on armrests, and starting position is given in percent of floor to knee height, resulting in a range from high $(140 \%)$ to low $(80 \%)$ seat heights. For additional description of tasks, see text.

from a side-lying position to sitting, or from an $80 \%$ FK with hand use.

\section{Bed Rise and Chair Rise Task Performance Time}

The differences in performance times between the various bed and chair rise tasks (see Table 3) were less striking but still statistically significant. Performance times tended to increase as the HOB or chair seat elevation declined and as 
hand use was limited. Compared to the $45^{\circ}$ referent, significant rise time reductions were found for $30^{\circ}(0.164 \pm$ $0.0235, P<.0001)$ and $0^{\circ}(0.547 \pm 0.0238, P<.0001)$. For comparison of $140,120,100$, and $80 \% \mathrm{FK}$, a significant seat height effect was noted $(-0.00796 \pm 0.000713, P<.0001)$, as was an effect for hand use $(1.12 \pm 0.138, P<.0001)$ and the interaction between seat height and hand use $(-0.00763 \pm 0.000994, P<.0001)$. This interaction suggests, as in the rise ability data, that both lowering the seat and limiting hand use potentiate each other in increasing chair rise difficulty.

\section{Relationship Between Self-Reported ADL Dependency and Bed and Chair Rise Performance}

Given the skewed distribution of the total number of bed and chair rise tasks successfully performed, total task score was re-scaled into a six-level variable, $\leq 16,17,18,19,20$, and 21 tasks completed. Self-reported dependency in transferring was a significant predictor of total number of rise tasks performed $(1.14 \pm 0.343, P<.001)$. In a subsequent model adding total number of self-reported ADL disabilities, number of ADL disabilities $(0.316 \pm 0.151, P<.04)$ was a significant predictor of total rise tasks performed, whereas transferring disability was no longer significant. The number of ADL disabilities also predicted essentially all timed chair rise performances (parameters ranging from 0.07 to 0.3 , $P$-values generally $<.002)$, but only selected bed rise tasks ( 30 and $45^{\circ}$ supine to sit at the edge of the bed, side lying to sitting, and supine to standing). Few chair or bed tasks correlated significantly with transferring disability.

\section{Test-Retest Reliability}

Test-retest reliability between the two baseline sessions was generally good. Simple kappas ranged from $0.6-1.0$ for rise ability (see Table 4). Exceptions were the two $80 \%$ seat height with hand chair rise (with and without cushion) tasks, where the kappa score dropped to 0.4. Kappas seemed higher (at 1.0) for tasks where hand use was allowed and at the elevated seat heights. Intraclass correlation coefficients (ICCs) of log-transformed performance times ranged from $0.6-0.9$, with less striking differences between tasks.

\section{DISCUSSION}

As expected, lowering HOB height and seat height increased bed and chair rise task difficulty, particularly when hand use was restricted, in this group of ADL-impaired older adults. A small group ( $8-10 \%)$ seemed dependent upon hand use for rise success. A number of studies have already found the importance of seat height in chair rise success when rising without the use of hands, ${ }^{10,28}$ but it seems that in "hand use" chair rises, seat height changes have less of an impact. Few data exist on the importance of HOB changes. The increasing lack of ability to sit up with no hand use as the HOB elevation declines suggests trunk flexion weakness, with particularly severe weakness in those unable to rise even at $45^{\circ} \mathrm{HOB}$ elevation. An increased emphasis on trunk function training, specifically strength, range of motion, and balance, may be useful in reducing future bed and chair rise performance decrements.

In subjects with rise difficulty, the use of the upper extremities to facilitate rising is critical, both in terms of the reducing the leg strength requirements and in terms of maintaining better postural control during the rise. ${ }^{12}$ Conditions
Table 4. A. Test-Retest Kappa Statistics of Ability to Successfully Complete Bed and Chair Rise Task

\begin{tabular}{|c|c|c|c|}
\hline \multirow[b]{2}{*}{ Bed Rise Task } & \multicolumn{3}{|c|}{ Starting Positions } \\
\hline & $45^{\circ}$ & $30^{\circ}$ & $0^{\circ}$ \\
\hline Supine to sit to edge & 1.0 & 1.0 & 0.9 \\
\hline Sit-up, with hands & 1.0 & 1.0 & 0.7 \\
\hline Sit-up, without hands & 0.8 & 0.9 & 0.7 \\
\hline Side-lying to sit & 0.6 & & \\
\hline Supine-to-stand & 0.9 & & \\
\hline \multirow[b]{2}{*}{ Chair Rise Task } & \multicolumn{3}{|c|}{ Use of Hands } \\
\hline & $\begin{array}{l}\text { With } \\
\text { Hands }\end{array}$ & \multicolumn{2}{|c|}{$\begin{array}{l}\text { Without } \\
\text { Hands }\end{array}$} \\
\hline $140 \%$ & 1.0 & \multicolumn{2}{|c|}{0.7} \\
\hline $120 \%$ & 1.0 & \multicolumn{2}{|c|}{0.9} \\
\hline $100 \%$ & 0.7 & \multicolumn{2}{|c|}{0.8} \\
\hline $100 \%$, tilt/recline & 0.7 & & \\
\hline $80 \%$, cushion & 0.4 & \multicolumn{2}{|c|}{0.7} \\
\hline $80 \%$ & 0.4 & \multicolumn{2}{|c|}{0.7} \\
\hline
\end{tabular}

Table 4. B. Test-Retest Intraclass Correlation Coefficients (ICCs) of Bed and Chair Risk Task Performance Time*

\begin{tabular}{llll}
\hline & \multicolumn{3}{c}{ Starting Positions } \\
\cline { 2 - 4 } \multicolumn{1}{c}{ Bed Rise Task } & $45^{\circ}$ & $30^{\circ}$ & $0^{\circ}$ \\
\hline Supine to sit to edge & 0.9 & 0.9 & 0.8 \\
Sit-up, with hands & 0.6 & 0.7 & 0.8 \\
Sit-up, without hands & 0.6 & 0.6 & 0.6 \\
Side-lying to sit & 0.6 & & \\
Supine-to-stand & 0.9 & & \\
\hline
\end{tabular}

\begin{tabular}{lcc}
\hline & \multicolumn{2}{c}{ Use of Hands } \\
\cline { 2 - 3 } Chair Rise Task & With Hands & Without Hands \\
\hline $140 \%$ & 0.7 & 0.7 \\
$120 \%$ & 0.6 & 0.7 \\
$100 \%$ & 0.8 & 0.7 \\
$100 \%$, tilt/recline & 0.7 & \\
$80 \%$, cushion & 0.8 & 0.7 \\
$80 \%$ & 0.8 & 0.7 \\
\hline
\end{tabular}

*ICCs represent comparison of log-transformed times (see text for additional details).

that limit the use of the upper extremities, either due to pain, weakness, or limited range (such as in osteoarthritis and stroke) will obviously have a major impact on transferring abilities. Based on the present data, chair and bed design parameters that enhance rising, such as adjustments for elevation of the seat height and head of the bed, might be more universally adopted in older adult resident settings, and not considered merely as part of a special purchase of medical equipment (such as with a hospital bed). Although beyond the scope of the present study, given the importance of upper extremity use in facilitating rises, further enhancement of upper extremity use in these disabled individuals might also 
be an important design parameter, such as through arm rest style and placement modifications.

Essentially all subjects were able to rise from positions where the starting surface was elevated as long as hand use was unlimited, such as in supine to sit-to-edge and sit up with hands at 45 and $30^{\circ} \mathrm{HOB}$ elevation, and in rising with hands from a seat height at 140,120 , and $100 \%$ FK. Not all subjects required these types of bed and chair adjustments to perform certain critical tasks. Even at $0^{\circ} \mathrm{HOB}$ elevation and $80 \%$ seat height, only $3-5 \%$ of subjects could not perform supine to sit-to-edge, supine to stand, or cushioned-seat with hands rises. Given a population of congregate housing residents with self-reported ADL dependency, the ability to perform these tasks may simulate the types of rise demands that these residents must deal with to maintain their present dwelling situation. These starting surface elevations are within the range of commercially available $\mathrm{HOB}$ and chair seat height adjustments, either formally (such as with a hospital bed) or informally (such as with the subject use of multiple pillows). ${ }^{9}$

Is it important that a number of subjects in the present study could not rise from a chair without the use of their upper extremities? The ability or inability to rise from a chair without the use of the upper extremities predicts future ADL-related outcomes. ${ }^{29}$ As in the present study, a number of studies have focused on rising from a chair without the use of hands ${ }^{30}$ and have shown progressively lower rise success as the seat is lowered. ${ }^{10}$ The inability to perform without-hand chair rise tasks may help to identify community-dwelling older adults who are declining in their chair rise ability, but may not predict how they perform in everyday chair rise tasks where hand use is usually critical. Based on our data, many of those who could not rise from a chair without hands could still rise from a chair while using their hands (even down to $80 \%$ FK). Thus, dependency on hand use may be a marker of progressive chair rise impairment but may not predict dayto-day, natural milieu chair rise performance.

Test-retest reliability seems reasonable for both the ableunable (kappa 0.6-1.0) and timed (ICCs 0.6-0.9) bed and chair rise performances in the present study. Similar reliability outcomes were found for bed rise time ${ }^{14}$ and for chair rise time (as reviewed in Bohannon ${ }^{31}$ ), particularly when a number of chair rise tasks are presented and when hand use is allowed.9,11 Recently, Jette et al. ${ }^{32}$ found a substantially lower ICC (0.25) for a single no-hand chair rise performed as quickly as possible, a novel task that is challenging for mobility-impaired older adults. We also found that certain challenging rise tasks, such as lowering the chair to $80 \% \mathrm{FK}$, lowers test-retest reliability. Part of the difficulty in comparing chair rise reliability data is that chair rise protocols vary in the number of rises used for a sampling period, ${ }^{31}$ although it seems that repeated chair rise times have good reliability. ${ }^{31,33-35}$ Future studies should carefully consider the number of tasks performed, as well as the starting conditions and instructions given, to ensure stable and meaningful measures of timed chair and bed rise task performance.

In terms of relating rise performance with self-reported disability, rise performance was more consistently related to total ADL disability rather than a single ADL item, transferring disability. This was particularly true for timed chair rise performance, with no apparent pattern favoring one particular chair height or hand use condition over another. Preliminary data suggest that more specific self-report measures of chair rise difficulty ${ }^{36}$ are better than the standard ADL transferring item in predicting chair rise performance.

Timed functional performance has become a powerful predictor of outcomes such as institutionalization, frank ADL disability, and mortality. ${ }^{25,37}$ The timing data in the present study suggest that as long as a subject can perform a task, intertask differences in timed performance may be statistically significant but are clinically small. Performance time in rising from a bed or chair is sensitive to therapy or exercise interventions in older (age $\geq 80$ ) and/or disabled older adults $^{38,39}$ but not in healthy older adults who rise quickly anyway, and a ceiling effect may be present. ${ }^{40}$ Timed bed rise and chair rise performance outcomes should thus be particularly useful in older adults with mild-to-moderate transferring impairment and in older adults with subtle yet clinically significant declines in or improvements in transferring function. Future studies should consider whether the findings in the present limited congregate housing cohort can be generalized to other milieus, such as assisted-living, outpatient, or rehabilitation settings.

\section{ACKNOWLEDGMENTS}

The authors wish to acknowledge the support of $\mathrm{Na}$ tional Institute on Aging (NIA) Claude Pepper Older Adults Independence Center Grant AG08808 as well as NIA Grant AG10542 and the Department of Veterans Affairs Rehabilitation Research and Development. The authors also thank Rhonda Keller, RN, and Allana Richmond, RN, for their participation during data collection. The authors also thank the following congregate housing facilities and their residents for their cooperation: Hillside Terrace, Lurie Terrace, Brookhaven Manor, Cranbrook Towers, Oakwood Commons, Henry Ford Village, and Presbyterian Village of Westland.

\section{REFERENCES}

1. Leon J, Lair T. Functional Status of the Noninstitutionalized Elderly: Estimates of ADL and IADL Difficulties. DHHS Publication No. (PHS) 90-3462. National Medical Expenditure Survey Research Findings 4 Agency for Health Care Policy and Research. Rockville, MD: Public Health Service, 1990.

2. Mehr DR, Fries BE, Williams BC. How different are VA nursing home residents? J Am Geriatr Soc 1993;41:1095-1101.

3. Feinstein AR, Josephy BR, Wells CK. Scientific and clinical problems in indexes of functional disability. Ann Intern Med 1988;105:413-420.

4. Liang MH, Jette AM. Measuring functional ability in chronic arthritis. Arthritis Rheum 1981;24:80-86.

5. National Institures of Health Consensus Development Conference Statement. Geriatric assessment methods for clinical decision-making. J Am Geriatr Soc 1988;36:342-347.

6. Hirsch $\mathrm{CH}$, Sommers $\mathrm{L}$, Olsen $\mathrm{A}$ et al. The natural history of functional morbidity in hospitalized older patients. J Am Geriatr Soc 1990;1296-1303.

7. Winograd CH, Lemsky CM, Nevitt MC et al. Development of a physical performance and mobility examination. J Am Geriatr Soc 1994;42:743-749.

8. Winograd $\mathrm{CH}$, Lindenberger $\mathrm{EC}$, Chavez $\mathrm{CM}$ et al. Identifying hospitalized older adults at varying risk for physical performance decline: A new approach. J Am Geriatr Soc 1997;45:604-609.

9. Alexander NB, Koester DJ, Grunawalt JA. Chair design affects how older adults rise from a chair. J Am Geriatr Soc. 1996;44:356-362.

10. Weiner DK, Long R, Hughes MA et. al. When older adults face the chairrise challenge. J Am Geriatr Soc 1993;41:6-10.

11. Alexander NB, Schultz AB, Warwick DN. Rising from a chair: Effects of age and functional ability on performance biomechanics. J Gerontol 1991;46, M91-98.

12. Schultz AB, Alexander NB, Ashton-Miller JA. Biomechanical analyses of rising from a chair. J Biomech 1992;25:1383-1391.

13. Alexander NB, Schultz AB, Ashton-Miller JA et al. Muscle strength and rising from a chair in older adults. Muscle Nerve 1997;(suppl 5):S56-S59. 
14. Alexander NB, Fry-Welch D, Ward $M$ et al. Quantitative assessment of bed rise difficulty in young and older women. J Am Geriatr Soc 1992;40:685691.

15. Alexander NB, Fry-Welch D, Marshall LM et al. Healthy young and old women differ in their trunk elevation and hip pivot motions when rising from supine to sitting. J Am Geriatr Soc 1995;43:338-343.

16. Alexander NB, Grunawalt JC, Carlos S, et al. Bed mobility task performance in older adults. J Rehab Res Dev, in press.

17. DeGowin EL, DeGowin RL. Bedside Diagnostic Examination, 2nd Ed. New York: Macmillan, 1971.

18. Kottke FJ, Stillwell GK, Lehmann JF. Krusen's Handbook of Physical Medicine and Rehabilitation, 3rd Ed. Philadelphia: WB Saunders, 1982.

19. Dejong RN. The Neurologic Examination, 4th Ed. Hagerstown, MD: Harper and Row, 1979.

20. Folstein M, Anthony JC, Parhad I et al. The meaning of cognitive impairment in the elderly. J Am Geriatr Soc 1985;33:228-235.

21. Sheikh JI, Yesavage JA. Recent evidence and development of a shorter version. Clin Gerontol 1986;5:165-172.

22. Smith LA, Branch LG, Scherr PA et al. Short-term variability of measures of physical function in older people. J Am Geriatr Soc 1990;38:993-998.

23. Fried LP, Ettinger WH, Lind B et al. Physical disability in older adults: A physiological approach. J Clin Epidemiol 1994;47:747-760.

24. Gill TM, Williams CS, Tinetti ME. Assessing risk for the onset of functional dependence among older adults: The role of physical performance. J Am Geriatr Soc 1995;43:603-609.

25. Guralnik JM, Ferrucci L, Simonsick EM et al. Lower-extremity function in persons over the age of 65 as a predictor of subsequent disability. N Engl J Med 1995;332:556-561.

26. Liang $\mathrm{KY}$, Zeger SL. Longitudinal data analysis using generalized linear models. Biometrika 1986;73:12-22.

27. Laird NM, Ware JH. Random-effects models for longitudinal data. Biometrics 1982;38:963-974.

28. Hughes MA, Myers BS, Schenkman BS. The role of strength in rising from a chair in functionally impaired elderly. J Biomech 1996;29:1509-1513.

29. Gill TM, Richardson ED, Tinetti ME. Evaluating the risk of dependence in activities of daily living among community-living older adults with mild-moderate cognitive impairment. J Gerontol A Biol Sci Med Sci 1995;50:M235-241.

30. Schenkman M, Hughes MA, Samsa G et al. The relative importance of strength and balance in chair rise by functionally impaired older individuals. J Am Geriatr Soc 1996;44:1441-1446.

31. Bohannon RW. Sit-to-stand test for measuring performance of lower extremity muscles. Percept Motor Skills 1995;80:163-166.

32. Jette AM, Lette $\mathrm{DU}, \mathrm{Ng}$ J et al. Are performance-based measures sufficiently reliable for use in multicenter trials. J Gerontol A Biol Sci Med Sci 1999;54: M3-6.

33. Hoeymans N, Wouters ERCM, Feskens EJM. Reproducibility of performance-based and self-reported measures of functional status. J Gerontol A Biol Sci Med Sci 1997;52:M363-368.

34. Tager IB, Swanson A, Satariano WA. Reliability of physical performance and self-reported functional measures in an older population. J Gerontol 1998;53:M295-300.

35. Tinetti ME. Performance-oriented assessment of mobility problems in elderly patients. J Am Geriatr Soc 1986;34:119-126.

36. Nyquist L, Alexander NB. Development and validation of a self-report measure of chair rise [abstract]. Gerontologist 1995;35:365.

37. Guralnik JM, Simonsick EM, Ferrucci L et al. A short physical performance battery assessing lower extremity function: Association with self-reported disability and prediction of mortality and nursing home admission. J Gerontol 1994;49:M85-94

38. Mulrow CD, Gerety MB, Kanten D et. al. A randomized trial of physical rehabilitation for very frail nursing home residents. JAMA 1994;271:519 524.

39. McMurdo MET, Rennie L. A controlled trial of exercise by residents of old people's homes. Age Ageing 1993;22:11-15.

40. Judge JO, Whipple RH, Wolfson LI. Effects of resistive and balance exercises on isokinetic strength in older persons. J Am Geriatr Soc 1994;42:937-946. 